Mushin, R. \& KeRR, V. J. (1954). J. gen. Microbiol. 10, 445-451.

\title{
Clotting of Gitrated Plasma and Citrate Utilization by Intestinal Gram-negative Bacilli
}

\author{
By ROSE MUSHIN AND VALERIE J. KERR
}

School of Bacteriology, University of Melbourne, Australia

\begin{abstract}
SUMMARY: Salmonella, shigella, alkalescens-dispar, proteus, paracolon and coliform strains were tested for the presence of a coagulase enzyme as manifested by the ability to clot plasma. The shigella and proteus strains examined gave negative results; a high percentage of the remaining strains clotted citrated plasma but this reaction was due to metabolism of citrate and subsequent liberation of calcium ions and not to a coagulase enzyme. Results depended on the bacterial strain and on the kind and dilution of plasma used. Utilization of citrate in citrated plasma was compared with the ability of the tested strains to attack citrate in Koser's ammonium citrate medium and in sodium citrate peptone medium. The Shigella and Proteus species examined failed to utilize citrate in any of the media under the conditions of the tests, Salmonella species gave fairly uniform results in the three media, while paracolon, coliform and alkalescens-dispar strains differed in their activity, the highest percentage of positive reactions being obtained in plasma-containing media.
\end{abstract}

In the course of a study of Gram-negative bacilli these organisms were examined to see whether they possessed coagulases capable of clotting plasma. A survey of literature showed that numerous bacterial species have been examined for plasma-coagulating ability. Conflicting results have been obtained, due possibly to different experimental conditions. In the present communication only intestinal Gram-negative bacilli will be considered.

Loeb (1903) used aseptically drawn goose-blood, which was centrifuged and diluted 1/10. He noticed the strong coagulating power of Staphylococcus aureus and that Salmonella typhi had no apparent effect, while Pseudomonas aeruginosa and Escherichia coli had some coagulating ability. Much (1908), in experiments with human plasma and citrate, fluoride or hirudin as anticoagulants, reported negative results with Sal. typhi, E. coli, Friedländer's bacillus and Proteus spp. Kemkes (1928) published negative findings in tests with oxalated plasma and the following organisms: Ps. aeruginosa, Ps. fluorescens, Sal. typhi, Shigella flexneri and Sh. dysenteriae. Lusena (1929) noted that some Sal. typhi cultures coagulated decalcified plasma. Gross (1931), found various bacteria, Sal. typhi, Sal. paratyphi, Ps. aeruginosa, shigella and proteus strains, negative in their action on rabbit plasma. Fisher (1936) investigated the coagulating properties of staphylococci on oxalated and citrated plasma and observed that contaminants such as some strains of Bacillus subtilis and Ps. aeruginosa caused clotting of rabbit but not human plasma, while Friedländer's bacillus, Alcaligenes sp., E. coli and Aerobacter aerogenes did not clot either. Reimer (1936) used various kinds of plasma without addition of anticoagulant and compared the clotting time of plasma mixed with bacterial cultures with that of control plasma. He found no 
analogy between activity on human and other animal plasmas; E. coli accelerated clotting of human plasma, while $S a l$. typhi and Sal. paratyphi-B inhibited clotting. Fredericq (1942) made experiments with oxalated plasma and recorded that $\boldsymbol{P}$ s. aeruginosa, $\boldsymbol{P}$ s. fuorescens and $\boldsymbol{B}$. subtilis had a coagulating effect, that of $P$ s. aeruginosa being the strongest.

Rita $(1945 a, b)$ recorded clotting of citrated plasma by Sal. typhi and other species of Salmonella but found no action on plasma to which oxalate or fluoride had been added. This writer concluded that strains which utilized citrate released calcium ion and thus caused plasma clotting. Rita (1945c), in tube experiments, noticed also the slow (8-10 hr.) clotting caused by salmonellas as compared with the quick (1-3 hr.) reaction caused by staphylococci.

Harper \& Conway (1948) investigated 8 strains of coliform and 5 of paracolon bacilli and found that 11 of the 13 strains clotted human citrated plasma at $37^{\circ}$ within $18 \mathrm{hr}$.; the clotting reaction was proved to be due to the breakdown of citrate with liberation of calcium ion and not to a coagulase. However, Krech (1952) demonstrated an active agent in filtrates of $\boldsymbol{E}$. coli. $\mathrm{He}$ used citrated plasma of man, horse, cow and guinea-pig and found that horse plasma was most actively coagulated and that a temperature of $c .16^{\circ}$ was the important factor in the test.

The present communication describes the investigation of a collection of Gram-negative intestinal bacilli, including salmonella, shigella, alkalescensdispar, proteus, coliform and paracolon strains, with regard to clotting action on citrated and heparinized plasma and citrate utilization.

\section{MATERIALS AND METHODS}

Organisms. The following strains were examined: 52 salmonellas, 34 shigellas (7 Sh. dysenteriae, 18 Sh. flexneri, $7 \mathrm{Sh}$. boydii, $2 \mathrm{Sh}$. sonnei), 4 alkalescensdispar group, 53 proteus (23 Pr. mirabilis, 25 Pr. morganii, 5 Pr. vulgaris), 140 paracolons (91 Paracolobactrum coliforme type I, 9 P. coliforme type II, $12 P$. intermedium type I, $5 P$. intermedium type II, $10 P$. aerogenoides type I, 11 irregular citrate-negative and 2 irregular citrate-positive) and 14 coliforms (E. coli type I). Salmonella strains originated from the National Collection of Type Cultures, shigella and alkalescens-dispar strains were sent by Dr Ewing, U.S.A., while proteus, paracolon and coliform strains were from our own collection isolated from normal and abnormal faecal specimens and classified according to Bergey's Manual of Determinative Bacteriology (1948).

Methods. Rabbit and human plasmas were tested. Rabbit blood was collected aseptically by cardiac puncture and mixed in the proportion $9 \mathrm{ml}$. blood with $1 \mathrm{ml}$. of $10 \%(\mathrm{w} / \mathrm{v})$ sodium citrate (final concentration $1 \%$ ). Human plasma was obtained from a blood bank and contained 4 vol. blood to 1 vol. of $2 \%(\mathrm{w} / \mathrm{v})$ sodium citrate (final concentration $0.4 \%$ ). In tests with heparinized plasma 4 drops of the anticoagulant were added to $20 \mathrm{ml}$. citrated human plasma. The citrate media used included Koser's (1924) ammonium citrate solution and citrate in Bacto-peptone basal medium (Kauffmann, 1951).

Slide coagulase tests were performed with undiluted citrated rabbit plasma. For tube coagulation experiments rabbit plasma was diluted $1 / 10$ or $1 / 5$ 
with normal saline; the human plasma was diluted $1 / 4$ or $1 / 2$ or used undiluted. In tube tests $0.5 \mathrm{ml}$. of appropriate plasma was added to $0.5 \mathrm{ml}$. of an $18 \mathrm{hr}$. culture of the required organism in Hartley's tryptic broth. The results were recorded after $24 \mathrm{hr}$. incubation at $37^{\circ}$; negative tubes were kept under observation for $\mathbf{3}$ days.

Each batch of plasma was tested for clotting capacity by adding 1 drop of $5 \%$ calcium chloride to $\mathbf{0 . 5} \mathrm{ml}$. plasma. Control slide and tube coagulase tests were included in which known coagulase-positive and coagulase-negative strains of staphylococci were used.

Utilization of citrate in Koser's medium at $37^{\circ}$ was considered to be positive when growth was evident after a third successive subculture by inoculation with a straight wire at $48 \mathrm{hr}$. intervals. Utilization of citrate in the citrate peptone medium was assessed with lead acetate indicator after incubation of the cultures in triplicate sets at $37^{\circ}$ for 2,7 and 14 days.

\section{RESULTS}

Clotting of citrated plasma. The slide coagulase tests were uniformly negative. Occasionally granulation slowly took place which at first glance could have been mistaken for clotting, but after some practice it became evident that late and doubtful reactions were non-specific and should be recorded as negative.

Table 1. Clotting reactions with citrated and heparinized plasma caused by Gram-negative organisms

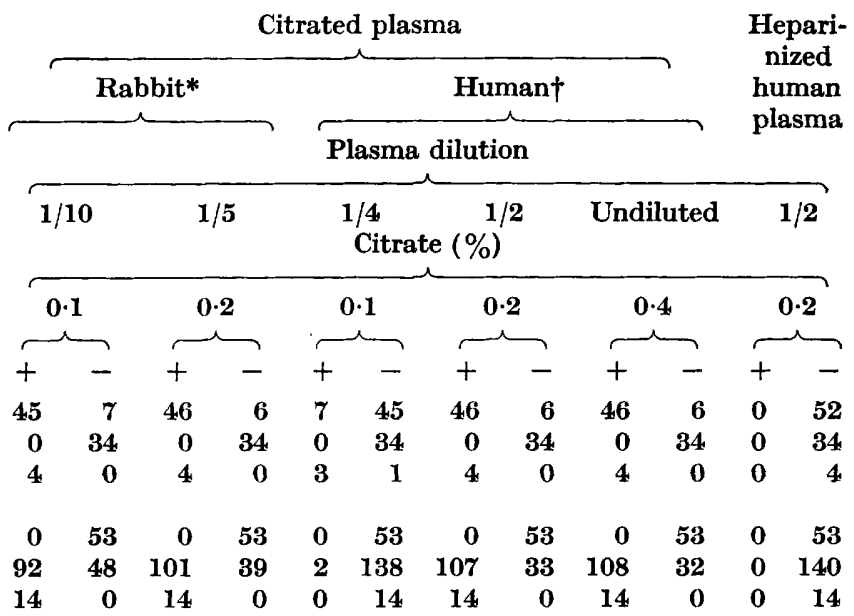

* Diluted $1 / 10$ in $10 \%(w / v)$ sodium citrate.

$\dagger$ Diluted $1 / 5$ in $2 \%(w / v)$ sodium citrate.

$+=$ clot; $-=$ no clot.

Table 1 shows that none of the strains investigated clotted heparinized plasma, thus showing the absence of coagulase under the conditions of the test. This was confirmed by tests with oxalated rabbit plasma; in no instance was a positive reaction obtained. 
All shigella and proteus strains were uniform in their inability to clot citrated plasma. All the $\boldsymbol{E}$. coli and alkalescens-dispar strains and the majority of salmonella and paracolon strains clotted citrated plasma within $24 \mathrm{hr}$. With citrated human plasma an increase in the number of positive readings was obtained with $\mathbf{1} / \mathbf{2}$ dilution of plasma (citrate concentration $\mathbf{0 . 2} \%$ ) as compared with 1/4 dilution, but with undiluted plasma only one paracolon strain gave an additional positive reaction. Citrated rabbit plasma was clotted by most strains at $1 / 10$ dilution (citrate concentration $0 \cdot 1 \%$ ) and only a few more strains clotted plasma at $1 / 5$ dilution. With a few exceptions strains clotted both citrated human and rabbit plasma; under the conditions of test 1 salmonella and 10 paracolon strains gave positive readings with human plasma only, while 1 salmonella and 3 paracolon strains acted only on rabbit plasma. Thus the ability to clot citrated plasma depended on the bacterial strain and also on the dilution and kind of plasma used, the concentration of citrate being the important factor. Harper \& Conway (1948) showed that clotting takes place when the concentration of citrate is less than that necessary for binding free calcium ions. The clot produced in our tests was soft, occasionally with a slight precipitate and unlike the fibrin-thread type of staphylococcal coagulum which retracts from the walls of the tube.

Additional tests were performed to find out whether a change of $\mathrm{pH}$ value was responsible for plasma clotting. Control plasma + sterile broth had a $\mathrm{pH}$ of 7.2. Clotted plasma cultures were shaken to break up the clot and the $\mathrm{pH}$ measured by means of a glass-electrode. Various cultures showed an increase of $\mathrm{pH}$ value to $7 \cdot 9-8 \cdot 4$; no clotting occurred in control media when the $\mathrm{pH}$ was adjusted to $8 \cdot 4$.

Of 140 paracolon strains tested, 16 liquefied gelatin; of these 9 did so within 1-2 days, but the remaining 7 strains acted more slowly. Eight active gelatin-liquefying strains did not clot plasma. Tests with these strains were repeated and the tubes examined every hour, but clot formation followed by solution was not observed.

Table 2. Utilization of citrate in various media

\begin{tabular}{|c|c|c|c|c|c|c|c|}
\hline \multirow[b]{4}{*}{ Strains } & & \multirow{2}{*}{\multicolumn{2}{|c|}{$\begin{array}{l}\text { Clotting of } \\
\text { plasma }\end{array}$}} & \multicolumn{4}{|c|}{ Citrate media } \\
\hline & & & & & & $\begin{array}{r}\text { Citrat } \\
\mathrm{m}\end{array}$ & $\begin{array}{l}\text { ptone } \\
\text { m }\end{array}$ \\
\hline & \multirow{2}{*}{$\begin{array}{l}\text { No. of } \\
\text { strains } \\
\text { tested }\end{array}$} & \multicolumn{6}{|c|}{ Positive reactions } \\
\hline & & No. & $\%$ & No. & $\%$ & No. & $\%$ \\
\hline Salmonella & $\mathbf{5 2}$ & 47 & 90 & 46 & 88 & 46 & 88 \\
\hline Shigella & 34 & 0 & $\mathbf{0}$ & 0 & 0 & $\mathbf{0}$ & 0 \\
\hline Alkalescens-dispar & 4 & 4 & 100 & 1 & 25 & 1 & 25 \\
\hline Proteus & 53 & 0 & $\mathbf{0}$ & 0 & $\mathbf{0}$ & 0 & $\mathbf{0}$ \\
\hline Paracolon & 140 & 111 & 80 & 31 & 22 & 42 & 30 \\
\hline Coliform & 14 & 14 & 100 & 0 & $\mathbf{0}$ & 1 & 7 \\
\hline
\end{tabular}

Citrate utilization. Table 2 shows the results of experiments on citrate utilization in various media: human and rabbit citrated plasma, Koser's ammonium citrate medium and citrate peptone medium. All the Shigella and 
three of the Proteus species (Pr. rettgeri was not tested) gave negative results in all media. Some proteus strains (Pr. mirabilis and Pr. vulgaris) showed growth in Koser's medium on first subculture, but growth was not maintained on the second transfer. Readings for the salmonellas ran parallel in all three media, with two exceptions: of 52 strains tested, 45 utilized citrate in all three media and 5 strains (Sal. paratyphi-A var. durazzo, Sal. abortus-equi, Sal. sendai and 2 strains of Sal. typhi), gave negative results; 1 strain of $S a l$. typhi attacked citrate in rabbit plasma only; Sal. carrau utilized citrate in all media except rabbit plasma. Paracolon, coliform and alkalescens-dispar strains gave a much higher percentage of positive reactions with citrated plasma than with Koser's or citrate peptone media. Only 2 paracolon strains utilized citrate in Koser's or citrate peptone media without being able to do so in plasma. Of the 29 paracolon strains which did not clot plasma, 20 were Paracolobactrum coliforme type I, one was $\boldsymbol{P}$. coliforme type II, one was $\boldsymbol{P}$. aerogenoides type I, one was $\boldsymbol{P}$. intermedium type II, and 6 were irregular citrate-negative types.

To assess the clotting time of rabbit plasma (diluted $1 / 10$ ), tests were carried out with a number of paracolon and coliform strains (Table 3). Only one paracolon strain produced a soft clot after $2 \mathrm{hr}$. incubation, the majority of paracolon and coliform strains gave positive reactions after $10 \mathrm{hr}$.; no additional positive results were recorded after $21 \mathrm{hr}$. In contrast to the slow action of the majority of paracolon and coliform strains, our control coagulasepositive staphylococci coagulated plasma in tube tests after $2 \mathrm{hr}$.

Table 3. The effect of incubation time on clotting reactions

Rabbit plasma (diluted 1/10) used to observe clotting

Time of reading (hr.)

\begin{tabular}{|c|c|c|c|c|c|c|c|c|c|}
\hline \multirow[b]{3}{*}{ Strains } & \multirow{3}{*}{$\begin{array}{l}\text { No. of } \\
\text { strains } \\
\text { tested }\end{array}$} & $\mathbf{1}$ & 2 & $\mathbf{3}$ & 4 & 10 & 21 & 24 & 48 \\
\hline & & \multicolumn{8}{|c|}{ Positive clotting reactions } \\
\hline & & & & & & & & & \\
\hline Paracolon & 78 & 0 & 1 & 8 & 14 & 51 & 66 & 66 & 66 \\
\hline Coliform & 13 & 0 & 0 & $\mathbf{0}$ & 0 & 10 & 13 & 13 & 13 \\
\hline
\end{tabular}

\section{DISCUSSION}

False positive coagulase reactions with citrated plasma by some salmonella strains (Rita, 1945 $a, b$ ) and by some paracolon and coliform strains (Harper \& Conway, 1948) were shown to be due to utilization of citrate with liberation of calcium ion. Evans, Buettner \& Niven (1952) observed that a similar reaction accounted for the clotting of plasma by certain streptococci.

Our experiments with Gram-negative intestinal bacilli show that the majority of salmonella, paracolon, coliform and alkalescens-dispar strains which clotted human or rabbit citrated plasma did so because of citrate breakdown. On the other hand, all Shigella species and three Proteus species did not cause clotting. Lominski, Conway, Harper \& Rennie (1947) pointed out that some $\boldsymbol{E}$. coli strains which failed to attack citrate in Koser's medium (ammonia as source of nitrogen) attacked citrate in the presence of a different source of nitrogen, e.g. peptone. The Shigella and Proteus species examined 
here gave negative results in the three citrate media; this may be helpful in diagnostic work, e.g. when it is difficult to classify an organism as shigella or paracolon, a positive citrate test would exclude shigella. Pr. mirabilis and Pr. vulgaris strains were reported (Rustigan \& Stuart, 1945; Cook, 1948; Bergey's Manual, 1948) to utilize citrate, but Kauffmann (1951) listed these species as citrate-negative. It is possible that proteus strains of faecal or non-faecal origin may differ in citrate utilization; our cultures were of faecal origin. It is clear from our findings that attention should be given to the conditions and details of these tests; in our experiments with Koser's medium a positive reading was recorded when growth appeared after three successive subcultures from inoculation with a straight needle at $48 \mathrm{hr}$. intervals. Rustigan \& Stuart (1945) observed that proteus strains grew at different rates on citrate medium. Cook (1948) mentioned that he inoculated Koser's citrate media with a straight wire. The published results, therefore, emphasize the need to standardize citrate utilization tests.

Rita (1945c) noticed that Sal. typhi strains varied in ability to clot plasma, and suggested that the division of $\boldsymbol{S a l}$. typhi into strains which clotted or did not clot citrated plasma might be useful in epidemiological investigations. Corda (1947) disagreed with this basis for differentiation because of the instability of the character. Our experiments also showed the unreliability of this criterion since results occasionally varied with the batch of plasma used. Krech (1952) described some $E$. coli strains which possessed an active agent in bacteria-free filtrates which was capable of coagulating plasma at room temperature but not at $37^{\circ}$. This, apparently, is a different reaction from that investigated in our study. The ability of Ps. aeruginosa, Ps. fluorescens, B. subtilis, Chromobacterium prodigiosum and actinomycetes to clot plasma is attributed by Fredericq $(1942,1946 a, b)$ to a different factor, namely a secretion of coagulase at $37^{\circ}$. Our work supports the suggestion of Harper \& Conway (1948) and of Evans et al. (1952) that, to avoid false positive coagulase reactions, tests should be performed with plasmas which contain anticoagulants other than citrate, e.g. oxalate or heparin.

\section{REFERENCES}

Bergey's Manual of Determination Bacteriology (1948). 6th ed. Edited by Breed, R. S., Murray, E. G. D. \& Hitchens, A. P. Baltimore: The Williams \& Wilkins Co.

Cook, G. T. (1948). Urease and other biochemical reactions of the Proteus group. J. Path. Bact. 60, 171.

Corda, M. (1947). Sulla coagulazione del sangue citratato ad opera della S. typhi. Boll. Soc. ital. Biol. sper. 23, 842.

Evans, J. B., Buettner, L. G. \& Niven, Jun., C. F. (1952). Occurrence of streptococci that give a false positive coagulase test. J. Bact. 64, 433 .

Fisher, A. M., (1936). The plasma coagulating properties of staphylococci. Johns Hopk. Hosp. Bull. 59, 393.

FredericQ, P. (1942). La coagulation du sang en l'absence de calcium. Arch. int. Physiol. 42, 73.

FredericQ, P. (1946a). Sur la coagulation du plasma oxalaté par les cultures de B. prodigiosus. C.R. Soc. Biol., Paris, 140, 1132. 
FredericQ, P. (1946b). Sur la coagulation du plasma oxalaté par les cultures d'Actinomyces. C.R. Soc. Biol., Paris, 140, 1166.

Gross, H. (1931). Der Plasmagerinnungsstoff der Staphylokokken. Zbl. Bakt. (1. Abt. Orig.), 122, 354.

Harper, E. M. \& Conway, N. S. (1948). Clotting of human citrated plasma by Gram-negative organisms. J. Path. Bact. 60, 247.

Kauffmann, F. (1951). Enterobacteriaceae. Copenhagen: Ejnar Munksgaard.

Kemkes, B. (1928). Plasmakoagulase und Pathogenität der Staphylokokken. Zbl. Bakt. (1. Abt. Orig.), 109, 11.

Koser, S. A. (1924). Correlation of citrate utilization by members of the colonaerogenes group with other differential characteristics and with habitat. J. Bact. 9, 59.

KRECH, U. (1952). Untersuchungen über die Koagulation von menschlichem und tierischem Plasma durch Bacterium coli. Z. ImmunForsch. 109, 206.

LOEB, L. (1903). The influence of certain bacteria on the coagulation of the blood. J. med. Res. 10, 407.

Lominski, I., Conway, N. S., Harper, E. M. \& Rennie, J. B. (1947). Utilization of citric acid by some so-called citrate-non-utilizing bacteria. Nature, Lond. $160,573$.

Lusena, M. (1929). Fermenti coagulanti di origine batterica. Boll. Ist. sieroter. Milano, 8, 559. Abst. in Zbl. Bakt. (1. Abt. Ref.), 1930, 99, 179.

Much, H. (1908). Über eine Vorstufe des Fibrinfermentes in Kulturen von Staphylokokkus aureus. Biochem. Z. 14, 143.

REIMER, K. voN (1936). Über charakteristische Unterschiede in der gerinnungsbeeinflussenden und fibrinauflösenden Wirkung lebender Bakterien. Zbl. Bakt. (1. Abt. Orig.), 136, 84.

RIta, G. $(1945 a)$. Richerche sulla coagulazione del plasma salato ad opera di alcuni ceppi di B. typhi. Boll. Soc. ital. Biol. sper. 20, 224.

RITA, G. (1945 b). Sulla natura del fenomeno della coagulazione del plasma citratato ad opera di alcuni ceppi di B. typhi. Boll. Soc. ital. Biol. sper. 20, 227.

Rita, G. $(1945 c)$. Sulla coagulazione del plasma citratato ad opera dei BB. paratifici e di altre Salmonelle. Boll. Soc. ital. Biol. sper. 20, 351.

Rustigan, R. \& Stuart, C. A. (1945). The biochemical and serological relationships of the organisms of the genus Proteus. J. Bact. 49, 419. 